\title{
Growth and Chlorophyll Content of Canola Plants Supplied with Urea and Ammonium Nitrate in Response to Various Nickel Levels
}

\author{
Ahmad BYBORDI ${ }^{1}$, Mohammad Nabi GHEIBI ${ }^{2}$ \\ 1) Baku State University, Faculty of Biology, 23 Z. Khalilov Street, 370148 Baku, Azerbaijan; abaybordy@yahoo.com \\ 2) Soil and Water Research Institute, Tehran, Iran; mngheibi@swri.ir
}

\begin{abstract}
Both the beneficial and the adverse effects of various nickel level supplements on growth and chlorophyll content of canola plants were evaluated while either urea or ammonium nitrate was supplied as the sole $\mathrm{N}$ source in the nutrient solutions. This study was arranged in completely randomized with three replications. Treatments included nutrient solution cultures containing urea and ammonium nitrate at the rate of $84 \mathrm{mg} \mathrm{N} \mathrm{L}^{-1}$ separately as nitrogen sources with four nickel levels as $\mathrm{NiSO}_{4} .6 \mathrm{H}_{2} \mathrm{O}_{\text {at }}$ the rates of $0,0.01,0.05$ and $0.1 \mathrm{mg} \mathrm{Ni} \mathrm{L}{ }^{-1}$. Plants were allowed to grow for 6 weeks then leaves chlorophyll content and shoots and roots fresh and dry weight were determined. Both plant growth and leaves chlorophyll content of the urea-fed plants increased significantly with the increase in nickel content up to $0.1 \mathrm{mg} \mathrm{Ni} \mathrm{L}^{-1}$. However, root fresh and dry weight increased up to $0.01 \mathrm{mg} \mathrm{Ni} \mathrm{L}^{-1}$ and started to decrease with further increase in solutions nickel content. Nickel did not affect these parameters with plants supplied with ammonium nitrate significantly. In these plants, the optimum nickel level for shoot growth and leaves chlorophyll content was $0.05 \mathrm{mg} \mathrm{L}^{-1}$ and for root fresh and dry weight was $0.01 \mathrm{mg} \mathrm{Ni} \mathrm{L}^{-1}$. Further increase in Ni concentration reduced growth. As a whole, plants received urea plus nickel performed better than those received ammonium nitrate plus nickel.
\end{abstract}

Keywords: nickel, canola, urea, ammonium nitrate, growth, chlorophyll content

\section{Introduction}

Urea is the most common forms of combined nitrogen fertilizer used in today's agricultural practices worldwide (Varina and Obrerza, 1993). In Iran, of the 2052 thousand tons of nitrogen fertilizer used in 2004, 1727 thousand tons $(84 \%)$ of which was in urea form (Malakouti, 2004). Before being hydrolyzed to ammonia and carbon dioxide by urease, urea can not be used in plant metabolism directly (Ciurli et al., 1999). High levels of urea are toxic to plant metabolism causing leaf burn (Krogmeier et al., 1989). One of the ways to overcome urea toxicity in higher plants is using nickel to increase urease activity (Bekkari and Pizelle, 1992; Marschner, 1995). Therefore, urea utilization must be accompanied by urease action.

Although urease was purified for the first time by Sumner in 1926, it is about 34 years that the role of nickel as the structural component of this enzyme has been recognized (Dixon et al., 1975). After Dixon and coworkers discovery, attentions started to focus on the role of nickel in plant metabolism. In 1976, Polacco and also in 1978 Gordon and co-workers reported the enhancing effects of nickel on plant growth and development when grown hydroponically and supplied with urea as nitrogen source. Shimada and Ando (1980) reported that when tomato and soya plants were grown in hydroponic cultures with insufficient nickel and supplied with urea as nitrogen source, urea was accumulated in their tissues and developed leaf tip necrosis. The role of nickel in urea metabolism in plant was reported by Walker and his co-workers in 1985. Many scientists have reported the beneficial effects of nickel on plants (Mengel and Kirkby 1978; Andreeva et al., 2001). Witte and Co-worker (2002) studied the effects of urease activity on nitrogen distribution and nitrogen loss after spraying potato plants with urea. They found a good correlation between urease activity and ${ }^{15} \mathrm{~N}$-metabolism. In this study, nitrogen metabolism was evaluated on the basis of $\mathrm{NH}_{3}$ accumulation.

Tan and Co-workers (2000) investigated the effects of different nickel levels on growth and $\mathrm{N}$-assimilation in tomato plants supplied with urea and nitrate as two different sources of nitrogen. Urease activity in leaves and roots of plants grown without nickel regardless of the form of nitrogen supplied, decreased significantly (Gerendas and Sattelmacher,1999).

Studies on the effects of nickel supply on growth, urease activity, urea accumulation and soluble amino acids in wheat, soya, rape, cucurbit, sunflower and rye have shown that without nickel, urease activity in all these six plants is very low resulting in considerable urea accumulation and also in lower plant dry weight and nitrogen content (Gerenedas and Sattelmacher,1997). In these plants, limited urease activity due to low nickel supply resulted in nitrogen deficiency symptoms. Besides the role of urease in 
54

plants receiving urea as nitrogen source, this enzyme is also important for hydrolyzing urea derived from ureides and arginine produced in cytokinins metabolism (Reinboth and Mothes, 1962; Walker et al., 1985; Polacco and Holland, 1993). Urea produced in these processes will cause leaf burn unless detoxified by urease (Eskew et al., 1983; Krogmeier et al., 1989; Stebbins et al., 1991). Urease activity is also very important when urea is applied as foliar spray. Many reports have pointed to the positive effects of urea spray on mulberry yield in relation to urease activity (Fotedar and Chakrabarty, 1985; Sarker and Absar, 1995).

When cereal and legumes are grown hydroponically, nickel has a positive effect on their performance (Brown et al., 1987 a; Eskew et al., 1984).

The main objectives of the present study are:

The influence of various nickel level on shoot and root fresh and dry weight and on chlorophyll content in canola plants grown in media containing two $\mathrm{N}$ sources (Urea and ammonium nitrate).

Finding the optimum nickel levels for maximum growth rate and chlorophyll content for each $\mathrm{N}$-sources used.

\section{Materials and methods}

This experiment was carried out with canola in a completely factorial randomized with three replications for each treatment. Treatments included nutrient solution cultures containing urea and ammonium nitrate separately as two nitrogen sources with four nickel levels $(0,0.01,0.05$ and $0.1 \mathrm{mg}$ /liter). Deionized water was used to prepare all nutrient solutions.

Tab. 1. Composition of nutrient solution

\begin{tabular}{cccc}
\hline Nutrient & $\mathrm{mM}$ & Nutrient & $\mathrm{mM}$ \\
\hline $\mathrm{N}\left(\mathrm{NH}_{4} \mathrm{NO}_{3}\right.$ or Urea $)$ & 3 & $\mathrm{Fe} \mathrm{EDDHA}$ & 0.02 \\
$\mathrm{~K}_{2} \mathrm{SO}_{4}$ & 2 & $\mathrm{MnSO}_{4}$ & 0.003 \\
$\mathrm{CaCl}_{2}$ & 1.5 & $\mathrm{ZnSO}_{4}$ & 0.002 \\
$\mathrm{MgSO}_{4}$ & 1 & $\mathrm{CuSO}_{4}$ & 0.001 \\
$\mathrm{NaH}_{2} \mathrm{PO}_{4}$ & 0.66 & $\mathrm{H}_{3} \mathrm{BO}_{3}$ & 0.024 \\
& & $\mathrm{NH}_{4} \mathrm{MO}_{4}$ & 0.0001 \\
\hline
\end{tabular}

Canola seeds (cv. SLM046) were placed on moist filter papers in covered Petri dishes and were allowed to germinate inside phytotron set at $23 \mathrm{C}^{\circ}$. After five days, germinated seeds were transferred to half strength Hoagland solution cultures in the greenhouse with average day/night temperatures $32 / 20 \mathrm{C}^{\circ}$. The nitrogen source in the solution cultures was ammonium nitrate. Seedlings with 5-6 leaves were transferred to 24 polyethylene pots containing the complete nutrient solution as given in Tab. 1 .

Nickel was added as $\mathrm{NiSO} 4.6 \mathrm{H} 2 \mathrm{O}$ at the rates of 0 , $0.01,0.05$ and $0.10 \mathrm{mg} \mathrm{Ni} \mathrm{L-1.} \mathrm{Solutions} \mathrm{were} \mathrm{renewed}$ weekly and the solutions $\mathrm{pH}$ were kept constant at $6.0 \pm 0.2$ using $1 \mathrm{M} \mathrm{NaOH}$ or $1 \mathrm{M} \mathrm{HCl}$. Plants were allowed to grow for six weeks. Before harvesting, the leaves chlorophyll content was determined by portable chlorophyll meter (SPAD-502 Minolta). Plants were harvested and were divided into shoots and roots. The shoots and roots fresh weights were determined. These plant materials were then dried immediately in an oven at $70 \mathrm{C}^{\circ}$ for 72 hours, and were then ground to a fine powder in a Wiley mill to pass through a 20-mesh sieve. The total Ni content in shoots and roots were determined by ICP (Inductively Coupled Plasma).

Statistical analysis was performed using analysis of variance, and the means were separated by Duncan's multiple range test (DMRT) at the $1 \%$ and $5 \%$ level.

\section{Results and discussion}

The shoots and roots Ni content in both urea and ammonium nitrate-fed plants increased significantly with the increase in Ni concentration in the solution (Fig. 1). The $\mathrm{Ni}$ concentrations in shoots and roots in urea-fed plants
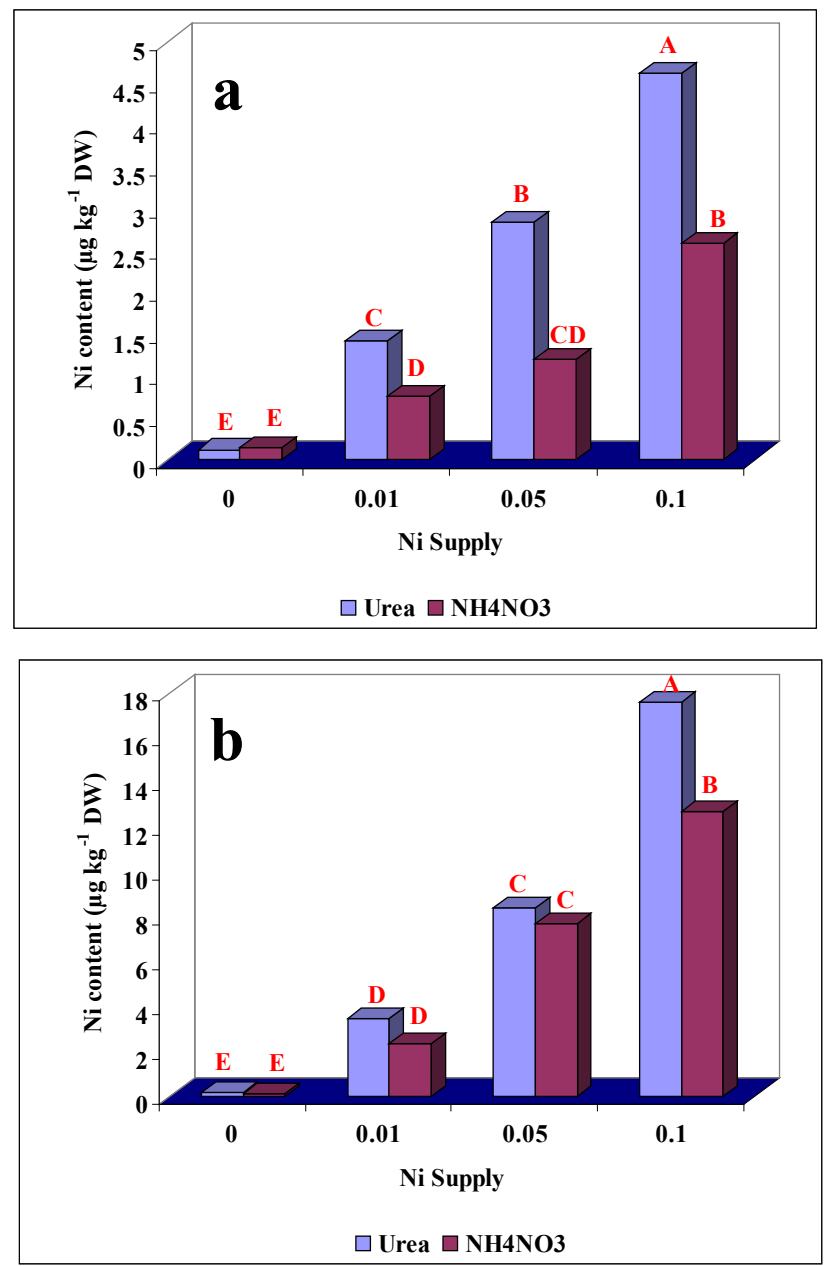

Fig. 1. Effect of nickel concentrations in the nutrient solution on the shoots (a) and roots (b) nickel content in canola plants supplied with urea or ammonium nitrate. Different letters refer to significant differences at the level of $\mathrm{p} \leq 0.05$ by Duncan's test. 
Tab. 2. Analysis of variance of parameters measured in canola

\begin{tabular}{ccccccc}
\hline \multicolumn{7}{c}{ Mean of squares (MS) } \\
\hline Parameters & df & chlorophyll & Roots fresh weight & Roots dry weight & Shoots fresh weight & Shoots dry weight \\
\hline Growth media & 1 & $184.37^{* *}$ & $453.09^{*}$ & $2.37^{\circ}$ & $1951.21^{\circ}$ & $39.01^{\circ}$ \\
Nickel levels & 3 & $90.58^{* *}$ & $526.22^{*}$ & $1.31^{\circ}$ & $945.78^{\text {ns }}$ & $19.17^{\text {ns }}$ \\
Nickel media & 3 & $23.62^{\text {ns }}$ & $452.33^{\circ}$ & $0.05^{\text {ns }}$ & $1009.51^{\text {ns }}$ & $24.13^{*}$ \\
Expt. error & 16 & 16.00 & 88.92 & 0.39 & 360.99 & 6.76 \\
C.V $\%$ & - & 11.35 & 18.21 & 23.94 & 13.27 & 16.97 \\
\hline
\end{tabular}

Note: : Significant at $5 \%$ level; ${ }^{* *}$ : Significant at $1 \%$ level ns: not significant
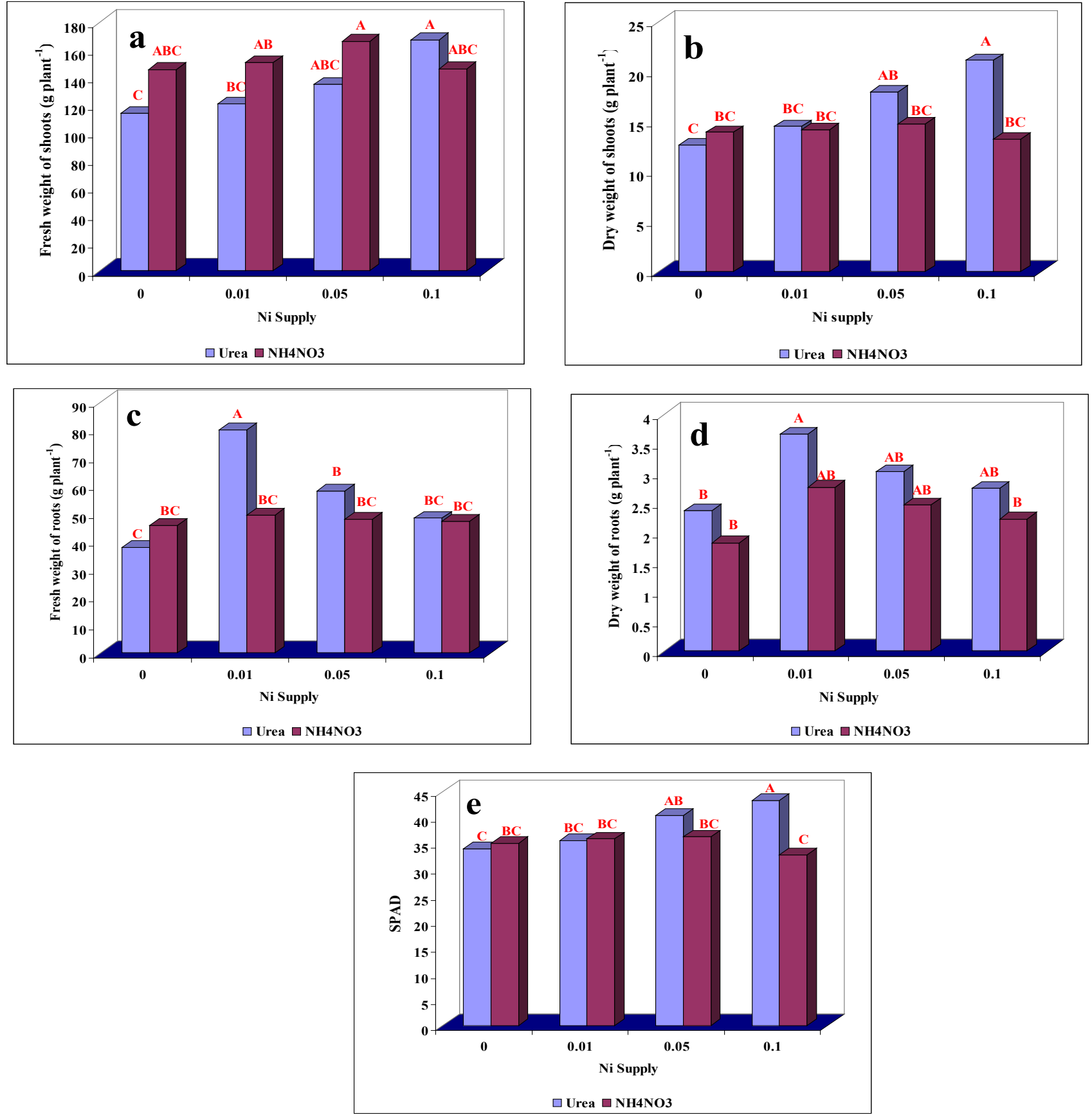

Fig. 2. Effects of Ni concentration on canola, shoots fresh weight(a), shoots dry weight(b), roots fresh weight(c), roots dry weight(d) and on chlorophyll content in leaves(e) grown in media containing urea or ammonium nitrate separately. Different letters refer to significant differences at the level of $\mathrm{p} \leq 0.05$ by Duncan's test. 
56

were more than those in ammonium nitrate-fed plants and also the $\mathrm{Ni}$ concentrations in roots were more than the Ni concentration in shoot in both urea and ammonium nitrate-fed plants. The highest Ni content $(14.03 \mu \mathrm{g}$ $\mathrm{kg}^{-1} \mathrm{Dw}$ ) occurred in the roots of urea-fed plants grown in solution containing $0.1 \mathrm{mgL}^{-1} \mathrm{Ni}$.

The effects of nickel levels on various parameters in canola, grown in nutrient media supplied with ammonium nitrate or urea are presented in Tab. 2.

The effects of $\mathrm{N}$-sources (ammonium nitrate or urea) on the parameters studied, except for chlorophyll content were significant at $5 \%$ level and on chlorophyll content was significant at $1 \%$ level. Also the effects of nickel levels on chlorophyll content and roots fresh weigh were significant at $1 \%$ level, and on roots dry weight was significant at $5 \%$ level and on shoots fresh and dry weight was not significant. The effects of interaction between growth media and nickel levels, except for roots fresh and shoots dry weight were not significant and on roots fresh and shoots dry weight were significant at 5\% level.

Although not significant at $1 \%$ level, plants growing in media containing ammonium nitrate and various nickel levels had both the highest shoot fresh and dry weight and also the amount of chlorophyll at the third nickel level ( $\left.0.05 \mathrm{mg} \mathrm{L}^{-1}\right)$ but started to decrease at higher nickel concentrations. Roots fresh and dry weight were the highest at the second nickel level $\left(0.01 \mathrm{mg} \mathrm{L}^{-1}\right)$,(Fig. 2).

In nutrient cultures containing urea, the effects of various nickel levels on canola shoots fresh and dry weight were significant at $1 \%$ level, and on roots fresh and dry weight and also on chlorophyll content were significant at $5 \%$ level. The shoots fresh and dry weight and the amount of chlorophyll were the highest at fourth nickel level $(0.1$ $\left.\mathrm{mg} \mathrm{L}^{-1}\right)$. The canola roots fresh and dry weights were the highest values at the second nickel level $\left(0.01 \mathrm{mg} \mathrm{L}^{-1}\right)$ and started to decrease with further increase in nickel content (Fig. 2).

The interaction effects between media and nickel levels revealed that at fourth nickel level, canola shoots fresh weight was higher in plants growing in media containing urea than those in ammonium nitrate. However, the difference was not significant at $5 \%$ level. The shoot dry weight was higher at third and fourth nickel levels ( 0.05 and 0.1 $\left.\mathrm{mg} \mathrm{L}^{-1}\right)$ in plants supplied with urea as compared with those supplied with ammonium nitrate. At fourth nickel level, this difference was significant at $1 \%$ level. Both roots fresh and dry weight were higher in plants supplied with urea than those treated with ammonium nitrate. The differences were significant ( $5 \%$ level) at second nickel level. However, further increase in nickel supply beyond 0.01 $\mathrm{mg} \mathrm{L}^{-1}$ resulted in a decrease in fresh and dry weight. The decrease was lower in plants treated with urea. Plants supplied with urea had higher chlorophyll content at third and fourth nickel levels than those supplied with ammonium nitrate. At fourth nickel level, this difference was significant at $1 \%$ level (Fig. 2).
Nickel content increased significantly in both shoots and roots with the increase in nickel concentration in nutrient solution (Fig.1). Nickel is readily taken up by plants. Up to a certain concentrations, the rate of nickel uptake is positively correlated with the external nickel concentrations (Morrison et al. 1980). The Ni concentration in shoots and roots of urea-fed plants were more than those supplied with ammonium nitrate. These results show that plants growing in media containing urea, application of nickel will probably result in higher urease activity and thus more urea-N will be available to the plants. Also the $\mathrm{Ni}$ concentrations were more in roots than in shoots in both urea and ammonium nitrate-fed plants. Besides nickel availability in the solution, the actual nickel content in plants depends on the plant species, plant parts and vegetative stage of plants (Gerendas and Sattelmacher, 1999). Accumulations of heavy metals by plants are known to be species specific and also depend on plant organs and plants developmental stage (Ovcharenko, 1997 and Kabata-Pendias 2001).

Although in growth media containing ammonium nitrate, nickel did not affect the parameters studied significantly (Fig. 2), the positive responses to certain nickel levels could be attributed to detoxification of urea produced in various metabolic pathways in plants (Reinboth and Mothes, 1962; Polacco and Holland, 1993). Urea produced in these metabolic pathways will result in urea toxicity if urease activity is limited by nickel deficiency (Eskew, et al., 1983; Krogmeier et al., 1989 and Stebbins et al., 1991). The positive nickel effects on shoot fresh and dry weight and the amount chlorophyll were at the third nickel level $\left(0.05 \mathrm{mg} \mathrm{L}^{-1}\right)$. Roots fresh and dry weights were the highest at the second nickel level $\left(0.01 \mathrm{mg} \mathrm{L}^{-1}\right)$ and started to decrease at higher concentrations (Fig. 2). Further nickel increase in growth media will result in nickel toxicity. At relatively high concentrations, nickel interferes and competes with essential divalent cations absorption such as Fe, $\mathrm{Mg}$, $\mathrm{Ca}$ and $\mathrm{Mn}$ by plant roots (Clarkson and Luttge, 1989).

Nickel supplement promoted the growth of urea-fed plants, and the growth promotion is probably due to the improvement of urea- $\mathrm{N}$ assimilation. The positive nickel effects on shoot fresh and dry weight and the amount of chlorophyll were at the fourth nickel level $\left(0.1 \mathrm{mg} \mathrm{L}^{-1}\right)$. Roots fresh and dry weights were the highest at the second nickel level $\left(0.01 \mathrm{mg} \mathrm{L}^{-1}\right)$ and started to decrease at higher nickel concentrations, (Fig. 2). The difference between shoots and roots responses to nickel levels is probably due to more roots sensitivity to higher nickel levels (Grendas and Sattelmacher, 1997 and 1999; Tan et al., 2000; Witte et al., 2002). In this study, chlorophyll concentration in urea-fed plants increased when nickel was added to the media. The increase in chlorophyll content demonstrates strongly the improvement in urea- $\mathrm{N}$ assimilation by the nickel supplement, because chlorophyll is an N-contain- 
ing compound (Barker, 1989). Minotti et al., (1994) demonstrated that the $\mathrm{N}$ status in plants can be assessed by the measurement of chlorophyll. The growth promotion is also attributed to more $\mathrm{N}$-urea assimilation.

The positive nickel effect on plants grown in urea or ammonium nitrate solution shown, canola shoots fresh weight was higher in plants growing in media containing urea than those in ammonium nitrate at fourth nickel level $\left(0.1 \mathrm{mg} \mathrm{L}^{-1}\right)$. The shoots dry weight was higher at third and fourth nickel levels $\left(0.05\right.$ and $\left.0.1 \mathrm{mg} \mathrm{L}^{-1}\right)$. Both fresh and dry weight of plants growing in media containing urea increased with the increase in nickel concentration which is probably related to higher urease activity. Higher urease activity and thus improved nitrogen efficiency and metabolism have probably contributed to observed differences. (Gerendas and Sattlmacher, 1997 and 1999; Tan $e t$ al., 2000; Witte et al., 2002).

Both canola roots fresh and dry weight were higher in plants supplied with urea than those treated with ammonium nitrate. However, further increase in nickel supply beyond $0.01 \mathrm{mg} \mathrm{L}^{-1}$ resulted in a decrease in fresh and dry weight. The decrease was less in plants treated with urea. The inhibitory effect of nickel which started at the third nickel level $\left(0.05 \mathrm{mg} \mathrm{L}^{-1}\right)$ could be due to its interference with plants metabolism and also to its competing effects on essential cations uptake by plant roots (Clarkson and Luttge, 1989).

The increase in plants performance receiving urea as compared to those grown in media containing ammonium nitrate could be attributed to higher urease activity by nickel and thus more nitrogen availability. Total chlorophyll content was also higher in plants supplied with urea plus nickel. At $0.1 \mathrm{mg} /$ liter, nickel improved $\mathrm{N}$-urea assimilation.

\section{Conclusions}

Our results indicate that the amount of nickel required for optimum canola growth depends on the forms of nitrogen supplied. When supplied with ammonium nitrate or urea, the amount of nickel needed is 0.05 and $0.10 \mathrm{mg}$ $\mathrm{L}^{-1}$ of nutrient solutions respectively.

\section{References}

Alagna, L., S. Hasnain, B. Pigott and D. Williams (1984). The nickel ion environment in jack bean urease. Biochem. J.220:591-595.

Andreeva, I., V. Govorina, S. Vinogradov and B. Yagodin (2001). Nickel in plants. Agricultural Chemistry. 3:82-94.

Barker, A. V. (1989). Genotypic response of vegetable crops to nitrogen nutrition. Hortscience. 24(4):584-591.

Bekkari, N. B. and G. Pizelle (1992). In vivo urease activity in Robinia Pseudoacacia. Plant Physiol. Biochem. 30(2):187192.
Brown, P. H., R. M. Welch and E. E. Cary (1987). Nickel: a micronutrient essential for higher plants. Plant Physiol. 85(3):801-803.

Clarkson, D. T. and U. Luttge ( 1989). Divalent cations, transport and compartmentation. Prog. Bot. 51:93-112.

Ciurli, S., S. Benini, W. R. Rypniewski, K. S. Wilson, S. Miletti and S. Mangani (1999). Structural properties of the nickel ion in urease: novel insights into the catalytic and inhibition mechanism. Coordination Chemistry Reviews. 190192:331-355.

Dixon, N. E., C. Gazzola, R. L. Blakeley and B. Zerner (1975). Jack bean urease (EC 3.5.1.5.). A metalloenzyme. A simple biological role for nickel. J. Am. Chem. Soc. 97(14):41314133.

Eskew, D. L., R. M. Welch and E. E. Cary (1983). Nickel: an essential micronutrient for legumes and possibly all higher plants. Science. 222:621-623.

Eskew, D. L., R. M. Welch and W. A. Norvall (1984). Nickel in higher plants. Further evidence for an essential role. Plant Physiol. 76:691-693.

Fotedar, R. K. and S. Chakrabarty (1985). Comparative studies on foliar and soil application of nitrogen on the leaf yield of mulberry. Indian J. Seri. 25:58-65.

Gerendas, J. and B. Sattelmacher (1997). Significance of Ni supply for growth, urease activity and the concentrations of urea, amino acids and mineral nutrients for urea-grown plants. Plant and Soil. 190:153-162.

Gerendas, J., Z. Zhu and B. Sattelmacher (1998). Influence of N and $\mathrm{Ni}$ supply on nitrogen metabolism and urease activity in rice (Oryza sativa L.). J. Exp. Bot. 49(326):1545-1554.

Gerendas, J. and B. Sattelmacher (1999). Influence of Ni supply on growth and nitrogen metabolism of Brassica napus L. growth with $\mathrm{NH}_{4} \mathrm{NO}_{3}$ or urea as $\mathrm{N}$ source. Annals of Botany. 83:65-71.

Gordon, W. R., S. S. Schwemmer and W. S. Hillman (1978). Nickel and the metabolism of urea by Lemna paucicostata Hegelm. 6746. Planta. 140:265-268.

Hogan, M. E., I. E. Swift and J. Done (1983). Urease assay and ammonia release from leaf tissue. Phytochemistry. 22(3):663-667.

Kabata-Pendias, A. (2001). Trace elements in soils and plants. 3th ed. CRC. Press. LLc. USA. pp.331.

Krogmeier, M. J., G.W. McCarty and J. M. Bremner (1989). Phytotoxicity of foliar applied urea. Proc. Natl. Acad. Sci. USA. 98(21):8189-8191.

Krogmeier, M. J., G. W. McCarty, D. R. Shogren and J. M. Bremner (1991). Effect of nickel deficiency in soybeans on the phytotoxicity of foliar applied urea. Plant and Soil. 135(2):283-286.

Malakouti, M. J. (2004). Fertilizer use by crop in Iran. Soil and Water Research Institute. Ministry of Agriculture, Iran.

Marschner, H. (1995). Mineral nutrition of higher plants. Second edition. Academic Press, London. 
58

Mengel, K. and E. Kirkby (1978). Principles of plant nutrition. International potash institute. Worblaufen-Bern. pp.593.

Minotti, P. L., D. E. Halseth and J. B. Sieczka (1994). Field chlorophyll measurement to assess the nitrogen status of potato varieties. Hortscience. 29(12):1497-1500.

Morrison, R., R. Brooks and R. Reeves (1980). Nickel uptake by Allysum species. Plant Sci. Lett. 17:451-460.

Ovcharenko, M. (1997). Heavy metals in the soil-plant fertilizer system. Printing House Proletarskij Svetoch. Moscow. pp. 290.

Polacco, J. C. (1976). Nitrogen metabolism in soybean tissue culture. Plant Physiol. 58:350-357.

Polacco, J. C. and M. A. Holland (1993). Roles of urease in plants cell. Int. Rev. Cytol. 145: 65-103.

Reinbothe, H. and K. Mothes(1962). Urea, ureides and guanidines in plants. Annu. Rev. Plant Physiol. 13:129-150.

Sarker, A. A. and N. Absar (1995). Foliar treatment effect of urea and micronutrients on mulberry (Morus sp.) and silkworm (Bombyx mori ). Sericologia. 35:713-720.

Shimada, N. and T. Ando (1980). Role of Nickel in Plant Nutrition(2). Effect of nickel on the assimilation of urea by plants. Jpn. J. Soil Sci. and Plant Nutr. 51:493-496.

Stebbins, N., M. A. Hollands, S. R. Cianzio and J. C. Polacco (1991). Genetic tests of the roles of the embryonic urease of soybean. Plant Physiol. 97:1004-1012.
Sumner, J. B. (1926). The isolation and crystallization of the enzyme urease. J. Biol. Chem. 69:435-441.

Tan, X. W., H. Ikeda and M. Oda (2000). Effect of nickel concentration in the nutrient solution on the nitrogen assimilation and growth of tomato seedling in hydroponic culture supplied with urea or nitrate as the sole nitrogen source. Scientia Horticulturae. 84:265-273.

Vavrina, C. S. and T. A. Obreza (1993). Response of chinese cabbage to nitrogen rate and source in sequential plantings. Hortscience. 28(12):1164-1165.

Walker, C. D., R. D. Graham, J. T. Madison, E. E. Cary and R. M. Welch (1985). Effects of Ni deficiency on some nitrogen metabolites in cowpeas (Vigna unguiculata L. Walp). Plant Physiol. 79:474-479.

Witte, C. P., S. A. Tiller, M. A. Taylor and H. V. Davies (2002). Leaf urea metabolism in potato. Urease activity profile and patterns of recovery and distribution of ${ }^{15} \mathrm{~N}$ after foliar urea application in wild-type and urease- antisense transgenics. Plant Physiology. 128:1129-1136. 